SHS Web of Conferences 12,01051 (2014)

DOI: $10.1051 /$ shsconf/ 20141201051

(C) Owned by the authors, published by EDP Sciences, 2014

\title{
Tourist Arrivals to Sabah by Using Fuzzy Forecasting
}

\author{
Zamali Tarmudi ${ }^{1}$, Tammie Christy Saibin ${ }^{2}$, Nasrah Naharu ${ }^{3}$, Nowyannie Willie D. Tamsin ${ }^{4}$ \\ 1,2,3,4 Faculty of Computer \& Mathematical Sciences, Universiti Teknologi MARA Cawangan Sabah, \\ 88997, Kota Kinabalu, Sabah.
}

\begin{abstract}
The aim of this paper is to investigate the existing tourist trend arrival in Sabah based on fuzzy approach. It focuses on the latest 12 years $(2002-2013)$ visitors arrival based on their nationality for forecasting purposes. Based on Sabah Tourism Board's data, the tourist arrival continue to grow annually but with an inconsistent number of arrival. This can be seen from the trend of tourist arrival from 2011 to 2012 . There is an increase in the number of arrival but only at $1.1 \%$ compared to the other years which are in the rank of $10-18 \%$ increase in number of arrival per year. Therefore, the purpose of this study is to predict the number of tourist arrival to Sabah. The study employs the modification of Fuzzy Delphi Method (FDM) and utilizes the flexibility of triangular fuzzy numbers (TFNs) as well as fuzzy averaging to deal with the yearly inconsistency numbers of visitor's arrival. Then, the trio levels of alpha $(\alpha)$-cut was used via linguistic variables to assess the confidence of decision made and to overcome the uncertainty of the input data sets. The analysis was carried out using fully data sets obtained from the official website of Sabah tourism board. Results show that our proposed forecasting approach offers a new dimension technique as compared to the traditional statistical method. It also derived more confident decision and precision forecast for Sabah tourism authority planning purposes.
\end{abstract}

\section{Introduction}

The tourism industry in Malaysia has been growth rapidly over the past few decades. Tourism has been one of the main contributors to the Malaysian's economy. Tenth Malaysia Plan (2011-2015) has identified tourism as a key economic area in making Malaysia top 10 in terms of global tourism receipts. In 2011, the tourism industry is the country's third largest foreign exchange earners [16]. The area of interest will be narrowed down to tourism in Sabah since most of the attractions are located in Sabah. One of the most attractive places in Sabah is the well-preserved rainforest. This is due to the geographical of Sabah where it covered the area of 7.3 million hectares and located on the northern point of the island of Borneo. Sabah also known as the second largest state in Malaysia and it shares border with East Kalimantan of Indonesia on the south and Sarawak on its southwest. 'Land below the wind' is the famous name for Sabah as it is located just below the typhoon prone region of the Philippines [14]. Furthermore, the famous trademark in Sabah is the Mount Kinabalu. It is the highest mountain in South East Asia at 4,101 meters. In addition, animal such as the Sumatran Rhinoceros, the Orang-Utan, the Mousedeer, the Flying Squirrel and the Barking deer are some very rare and protected, endangered species that can be found in Sabah. The Rafflesia can also be found in Sabah [14]. 
Apart from the nature beauty in Sabah, multiculturalism is another Sabah's added value for tourist attraction [14]. Tourist can witness how these multi ethnic groups live together peacefully. The largest ethnic groups that make up Sabah's society are Kadazan-Dusun, followed by Bajau and Murut. Sabah is a place that you can call paradise because nature and man come together. Be it at the tropical rainforests, beautiful beaches, variety of cultural heritage, delicious Malaysian cuisine, or the welcoming spirit of the Sabah people, all of this form Sabah to a paradise place to be visited.

Sabah is still successful in maintaining the virginity of its flora, fauna and its beaches, even though the tourism industry in Sabah has been expanding in recent times. Sabah richness has made it as a main tourist attraction in Malaysia. Recently, the number of tourist have increased by $17.6 \%$ from year 2012 to year 2013 and about 293641 tourists have visited Sabah only for the first quarter of the year 2014 [14]. It can be clearly seen that Sabah has a higher potential in tourism development.

In literatures prospective for instance, Lee and Chang [2] states that the growth in the tourism industry will trigger all the economic growth not only in term of foreign currency inflow but this will offer a varieties of job opportunities to Sabah residents. Hence, the local authorities should focus more on the tourism development for their country. Realizing the great potential for Sabah, a research to predict the number of tourist arrival for next year will be conducted.

Forecasting is important in tourism industry due to its perishable nature [8,5,4]. Empty buses, transportation, unused holiday tour package, and any tourist entertainment facilities cannot be stockpiled. If there are no tourist means there are no potential sales and it is lost forever [5]. In addition, the information obtained in forecasting tourist arrivals can be used by the government especially in the promoting activities $[17,4]$ and tourism related industry $[5,8]$.

Forecasting tourist arrivals can be applied either using quantitative or qualitative methods. This study will focus on quantitative methods. Studies published shown that the most commonly used methods are econometric methods such as vector auto regressive (VAR) [5] or time series models such as ARIMA and GARCH. Chen et al. [8] used adaptive network based fuzzy inference system (ANFIS) meanwhile; Pai et al. [11] used the novel hybrid system. This system combines the fuzzy cmean (FCM) and logarithm least squares support vector regression (LLS-VCR) to forecast tourist arrivals.

Based on the above literatures, forecasting the tourist arrival using Fuzzy Delphi Method (FDM) rarely been used. FDM method will utilize the flexibility of triangular fuzzy numbers (TFNs) as well as fuzzy averaging to forecast the Sabah tourist arrival. Thus, this paper aimed to forecast the visitors arrival to Sabah based on 12 years datasets, from 2002 to 2013. It is believed that the result produced will help the authorities especially in tourism related to make a strategic planning. To do so, this paper is structure as follows; section 1 and 2 both discussed about the background and the problem statement, respectively. Section 3 proposed a brief background of FDM followed by Section 4 which elaborates the implementation of the proposed method based on a case study in Sabah. Finally in Section 5, a brief discussion and the conclusion have been carried out.

\section{Problem Statement}

Sabah's tourism industry has been an important contributor to the Sabah's economy and also Malaysia's economy as a whole. Sabah is one of the most important tourist destinations in Malaysia. Tourism is a sector that has been recognized as one of the main important service industries in the world of today [15].Tourism in Sabah effects positively on the Malaysian economy for increasing foreign exchange earnings, and employment opportunities [7]. Based on Sabah Tourism Board's data, the tourist arrival continue to grow annually but with an inconsistent number of arrival. This can be seen from the trend of tourist arrival from 2011 to 2012. There is an increase in the number of arrival but only at $1.1 \%$ compared to the other years which are in the rank of $10-18 \%$ increase in number of arrival per year. Therefore, the purpose of this study is to predict the number of tourist arrival to Sabah. Accurate forecasts of tourist arrival can help the government to ensure the availability of 
tourism demand in Sabah is consistent as well as to help them to make a strategic planning for Sabah's tourism industry. This study proposed the application of Fuzzy Delphi Method (FDM) because this method is rarely been used and it helps to average the forecast of visitors arrival. This method provides an alternative tool to help the government with their strategic planning in tourism related.

\section{Our Proposed Method}

\subsection{A Brief Background}

The Fuzzy Delphi Method (FDM) was originally introduced by Kaufman and Gupta [1]. The method quite successful applied in various application such as; tourism website content personal presentation [3], new technology product evaluation [6], dry bulk freight predictions [10], constructing road safety performance indicators [18], etc. The method actually generalization of classical method known as Delphi method developed by Dalkey and Helmer [9] for forecasting purposes especially in mathematical sciences. However, in this paper we modified the classical FDM for forecasting tourist's arrival in five steps depicted in Figure 1.

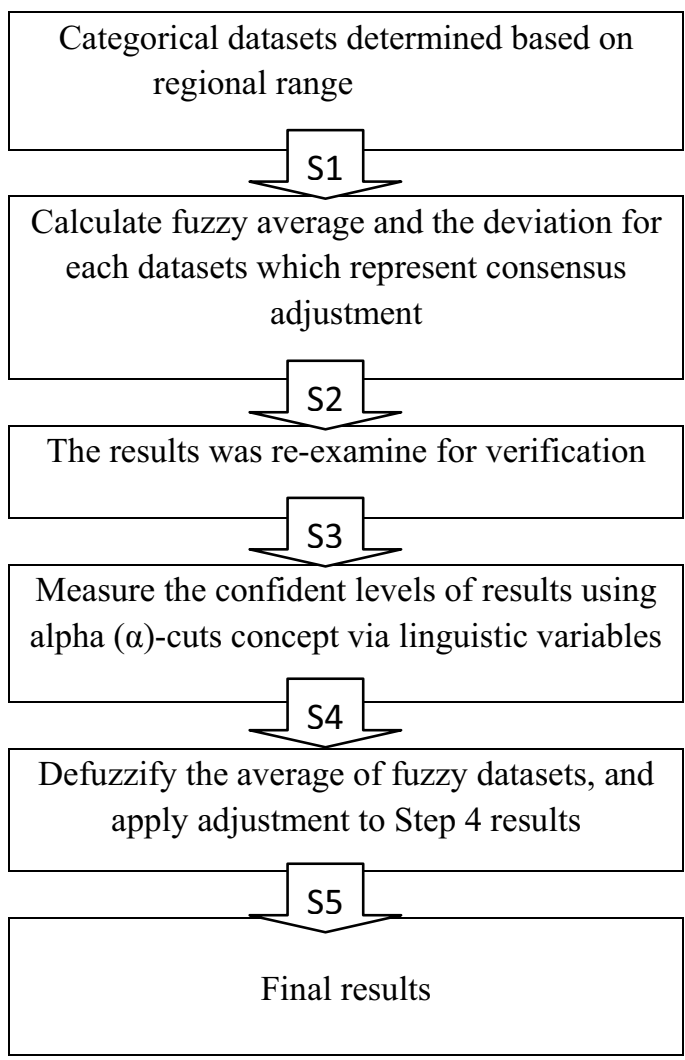

Figure 1. The overall steps of modified FDM 


\subsection{Constructing the Level of Confidence Via Linguistic Variables}

The confident decision is recognized as a vital component to be considered before proposing any forecasting measures. In this study we have constructed the linguistic variables to representing three difference confident situations as shown in Table 1.

Table 1. Linguistic expression of three level of confidence

\begin{tabular}{l|c}
\hline Linguistic variables & TFNs derived from $\left(\boldsymbol{a}_{\mathbf{1}}, \boldsymbol{a}_{\mathbf{2}}, \boldsymbol{a}_{\mathbf{3}}\right)$ \\
\hline Very optimistic $($ VO) & $\left(a_{1},\left(a_{2}+3 a_{1}\right) / 4, a_{3}\right)$ \\
\hline Neutral $(N)$ & $\left(a_{1}, a_{2}, a_{3}\right)$ \\
\hline Very pessimistic $($ VP $)$ & $\left(a_{1},\left(a_{2}+3 a_{3}\right) / 4, a_{3}\right)$ \\
\hline
\end{tabular}

Then, we utilize these concept based on TFNs to measure the three different level of confident for respective analysis results. In order to incorporate the level of confident in the proposed approach, we looked at the score matrix at $\alpha$-level as:

$$
\tilde{S_{\alpha}}=\left[\begin{array}{c}
\sim \\
x_{i j}
\end{array}\right]_{\alpha},
$$

where $\left.\tilde{x}_{i j}\right|_{\alpha}$ is the triangular fuzzy number derived from $\tilde{x}_{i j}^{r}$ under three difference of linguistic variables, respectively (i.e., $V O \approx \alpha=0.80, N \approx \alpha=0.50$ and $V P \approx \alpha=0.20$ ) by Equation-(1).

\section{Implementation Via A Case Study}

\subsection{Data Collection}

The data collection obtained directly from Sabah Tourism Board official website. The website provides a detail monthly basis the numbers of visitor arrival to Sabah for latest 12 years (i.e., 2002 2013) which is categorized by their nationality. Since the available datasets are solely based on the visitor's arrival, thus we use the $75.2 \%$ rate of overall arrivals to Sabah are believed involve directly in tourism activities or so-called tourists [13]. The datasets have been categorized based on each three sequences years for fuzzify purposes using TFNs. Then, the analysis performed using five steps as elaborated in sub-section 3.1 above.

\subsection{The Analysis and Results}

The analysis employs the modification of FDM and the datasets have been categorized into 6 regions; i) Oceana, ii) Europe, iii) America, iv) Asia, v) Malaysian, and vi) Others. Here are the complete analyses using five step-by-step procedures: 
Step 1: Categorical datasets determined based on quarterly basis and regional range

The entire datasets until latest 12 years (i.e., 2002 - 2013) have been compiled and categorized based on three years data for each range. For instance, datasets from year 2002 to 2004 will categorize in the same range to suit to the TFNs form. Then, the same technique will employs for the entire datasets for each region.

Step $2 \& 3$ : Calculate the fuzzy average, the deviation and re-examine (if necessary) for each datasets which represent consensus adjustment. Table 2 shows the example of average visitor's arrival for Oceana region (i.e., Australia \& New Zealand).

Table 2. The average of visitor's arrival in terms of TFNs form (2002 - 2013)

\begin{tabular}{l|c|c|c}
\hline Oceana $_{\text {region }}$ & 21,483 & 26,705 & 37,035 \\
\hline
\end{tabular}

Step 4: Measure the level of confidence results using alpha( $\alpha)$-cuts concept via three linguistic variables as define in Table 1 and employ by Equation -(1). Table 3 shows the result for Oceana region.

Table 3. The three level of confidence (i.e., $V O, N, V P$ ) for Oceana region

\begin{tabular}{l|c|c|c}
\hline \multirow{4}{*}{ Oceana $_{\text {region }}$} & \multicolumn{3}{|c}{ Very optimistic (VO) } \\
\cline { 2 - 4 } & 21,483 & 22,789 & 37,035 \\
\cline { 2 - 4 } & 21,483 & \multicolumn{3}{|c}{ Neutral $(N)$} \\
\cline { 2 - 4 } & \multicolumn{3}{|c|}{ Very pessimistic (VP) } \\
\cline { 2 - 4 } & 21,483 & 34,452 & 37,035 \\
\hline
\end{tabular}

Step 5: Defuzzfy average fuzzy set, and apply adjustment to Step 4 results (if necessary). In this study we utilize the defuzzfy $\left(D_{x} \sim\right)$ method [12] given by Equation -(2) as

$$
D_{x \sim}=\left(a_{1}+a_{2}+a_{2}+a_{3}\right) / 4
$$

Next, the defuzzifying process have been computed to derive the crisp values given as follows (see Table 4)

Table 4. The crisp values based on three level of confidence (i.e., $V O, N, V P$ )

\begin{tabular}{l|c|c|c}
\hline Level of confidence & $V O$ & $N$ & $V P$ \\
\hline Oceana $_{\text {region }}$ & 26,024 & 27,982 & 31,855 \\
\hline
\end{tabular}

Due to very limited space allowed in this paper, only Oceana region results analysis shown for an illustration purposes. The final results of visitor's trend arrival in Sabah for each region combine with three difference level of confidence (i.e., ' $V O$ ', ' $N$ ', ' $V P$ ') shown in Figure 2 a) and b), respectively. 
(a)

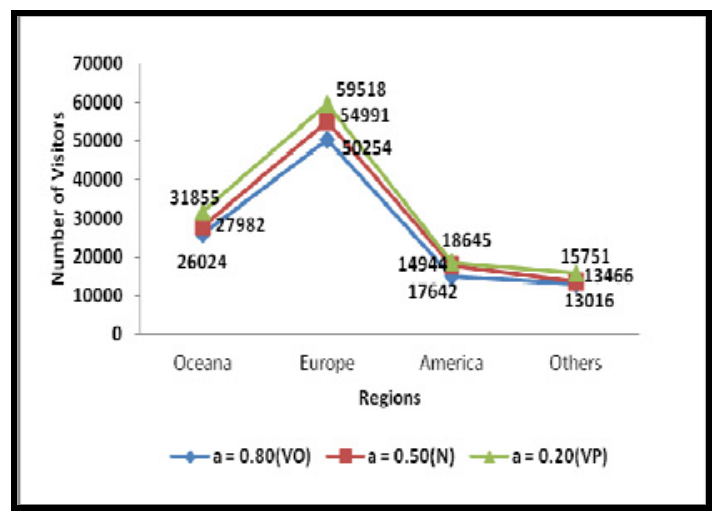

(b)

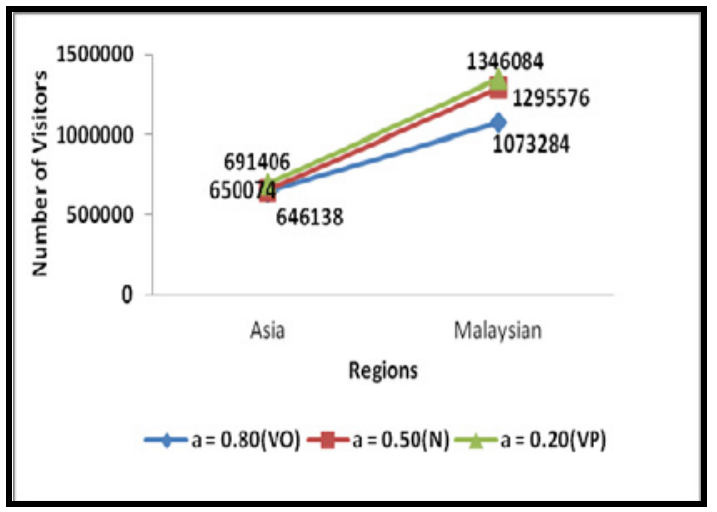

Figure 2. Overall trend of visitor's arrival based on three difference level of confidence for each region

Based on $75.2 \%$ rate of total visitor's arrival in Sabah [13], the normal confident level (i.e., Neutral $(N)$ ) of tourists arrival forecasting for all 6 regions given in Table 5. It was clear seen that the local tourists (i.e., Malaysian) are totally dominance in terms of numbers (i.e., 974,273) and the Sabah tourism authority should taken appropriate actions to maintain this momentum for state beneficial in economic purposes.

Table 5. Tourists arrival forecasting for neutral $(N)$ level of confident

\begin{tabular}{l|c|c|c|c|c|c}
\hline Region & Asia & Oceana & Europe & America & Malaysian & Others \\
\hline Level of confident & \multicolumn{5}{|c}{ Neutral $(N) \approx \alpha=0.50$} \\
\hline No. of arrival & 488,856 & 21,042 & 41,353 & 13,267 & 974,273 & 10,126 \\
\hline
\end{tabular}

a)

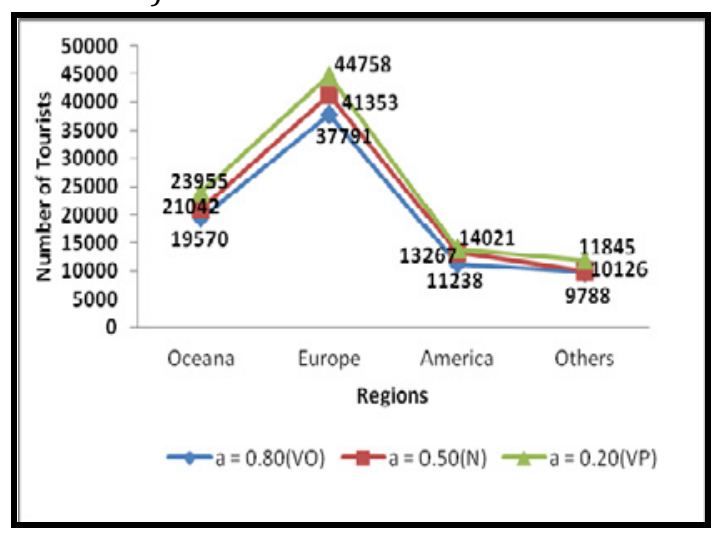

b)

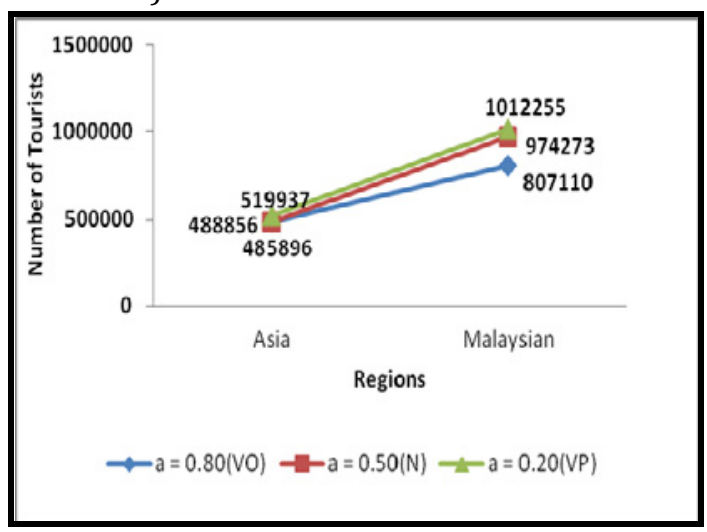

Figure 3. Overall forecasting of tourist's arrival based on three difference level of confidence for each region 
Next, Figure 3 a) and b) show the detail of entire tourist arrival forecast in Sabah based on three level of confidence (i.e., $V O, N, V P$ ), respectively. Meanwhile, Figure 4 shows the comparison forecasting of tourist arrival in Sabah between three region category (i.e., Malaysian, International, and others) based on three level of confidence. By using the proposed three difference of level of confidence, the tourism board or so-called decision-makers(DMs) can choose their preference in terms of expected number of arrivals based on their believe and experiences for planning purposes.

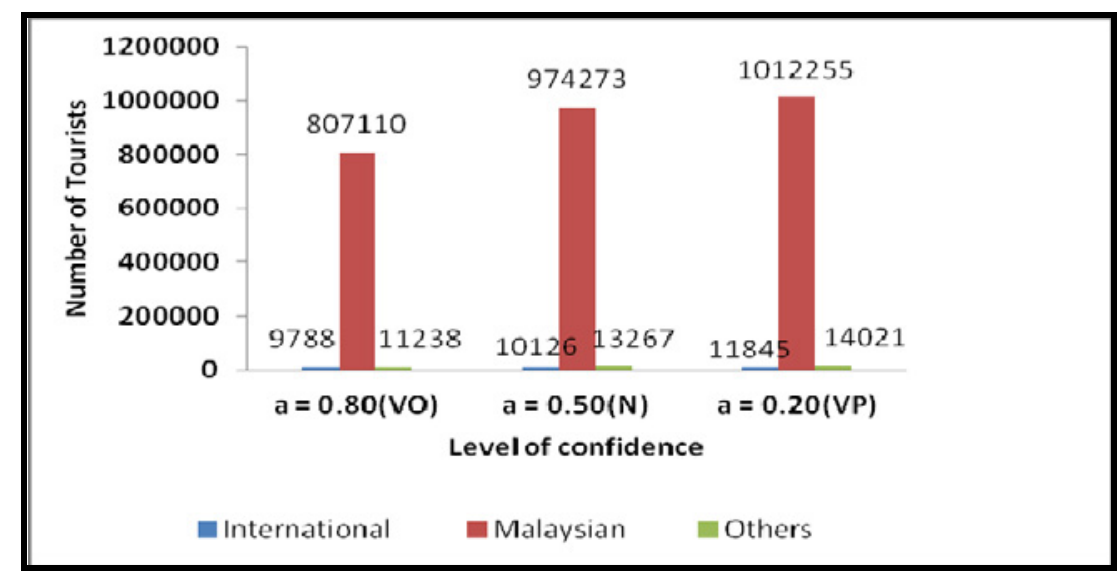

Figure 4. The comparison forecasting between three different region categories

\section{Conclusion}

In this paper we have proposed the modified fuzzy Delphi method (FDM) based on the classical Delphi method for forecasting purposes. Since the available datasets generally involve uncertainty, it is important to incorporate with fuzzy approach to derive comprehensively in any proposed method. The analysis was carried out using fully data sets obtained from the Sabah tourism board official website. From the empirical study, it can be clearly seen that the utilization of long terms datasets (i.e., 12 years) is more comprehensible in terms of final forecast output. Also the results show that our proposed forecasting approach offers a new dimension technique as compared to the traditional statistical method. Equipped by the three alternative level of confidence in analysis, the Sabah Tourism Board have the flexibility to estimate the future tourist arrival to Sabah based on their preference level of believed as well as their past experiences. As a result, it can derive more confident decision and precision forecast for Sabah tourism authority planning purposes such as to relook and improved the current government approach.

\section{References}

1. A. Kaufman, \& M. M. Gupta. Fuzzy Mathematical Models in Engineering and Management Science, North-Holland, Amsterdam (1988)

2. C. C. Lee \& C. P. Chang. Journal of Tourism Management. Tourism development and economic growth: A closer look at panels. 29, 180-192 (2008) 
3. D. K. Kardaras, B. Karakostas, \& X. J. Mamakou. Experts Systems with Applications. Content Presentation personalization and media adaptation in tourism web sites using Fuzzy Delphi Method and Fizzy Cognitive Maps, 40: 2331-2342 (2013)

4. E. Hadavandi, A. Ghanbari, K. Shahanaghi, S.A. Naghneh. Journal of Tourism Management. Tourist arrival forecasting by evolutionary fuzzy systems. 32, 1196- 1203 (2011)

5. H. Song \& S. F. Witt. Journal of Tourism Management. Forecasting international tourist flows to Macau. 27, $214-224$ (2006)

6. J. Cho \& J. Lee. Experts Systems with Applications. Development of a New Technology Product Evaluation Model for Assessing Commercialization Opportunities using Delphi method and Fuzzy AHP approach, 40: 5314-5330 (2013)

7. M. A. H. Bhuiyan, C. Siwar, S.M. Ismail \& R. Islam. Australian Journal of Basic and Applied Sciences. Potentials of Islamic Tourism: A case Study of Malaysia on East Coast Economic Region, 5, 1333-1340 (2011)

8. M. S. Chen, L. C. Ying, \& M.C. Pan. Journal of Expert Systems and Applications. Forecasting tourist arrivals by using the adaptive network-based fuzzy inference systems. 37, $1185-1191$ (2010)

9. N. C. Dalkey \& O. Helmer, Management Science. An Experimental Application Method to the Use of Experts, 9,3: 458-467(1963)

10. O. Duru, E. Bulut, \& S. Yoshida. Experts Systems with Applications. A Fuzzy Extended Delphi method for adjustment of statistical time series prediction: An Empirical Study on Dry Bulk Freight Market Case, 39: 840-848(2012)

11. P.F. Pai, K.C. Hung \& K.P. Lin. Journal of Expert Systems with Applications. Tourism demand forecasting using novel hybrid system. 41, 3691-3702. (2014)

12. S. M. Chen, Fuzzy Sets Systems Evaluation. Weapon Systems using Fuzzy Arithmetic Operations, 77: 265-276 (1996)

13. Sabah Tourism Board, 2011, Demographic Profiles of International Visitors, Research Division for Sabah Tourism Board (April, 16 2013).

14. Sabah Tourism Board Official Website. Retrieved on June 25, 2014 from www.sabahtourism.com/essentials/about-sabah.

15. Schumacher, H. J. (2007, June 15). Let's Talk Europe: Ecotourism. Business World. p. S1/6 (2007)

16. Tourism Malaysia Corporate Website. (2012). Tourism Malaysia welcomes Tiger Woods and world top golfers to CIMB Classic 2012. Retrieved on August 31, 2014 from http://corporate.tourism.gov.my/mediacentre

17. V. Cho. Journal of Tourism Management. A comparison of three different approaches to tourist arrival forecasting. 24, $323-330$ (2003)

18. Z. Ma, C. Shao, S. Ma, \& Z. Ye. Experts Systems with Applications. Constructing Road Safety Performance Indicators using Fuzzy Delphi Method and Grey Delphi Method, 38: 15091514(2011) 